\title{
ENTRE AS INTENSIVIDADES DA VIDA E O "ROÇAR" DA MORTE: UMA CARTOGRAFIA DE EXPERIÊNCIA COM PSICOATIVOS
}

\author{
Maria Juracy Filgueiras Tonel ${ }^{\star}$ \\ Fernando Luiz Salgado da Silva $\star \star$
}

\begin{abstract}
Resumo
Este trabalho é fruto de uma pesquisa de Iniciação Cientifica, financiado pelo CNPQ em 2008, na qual investiga-se processos de produção de subjetividade na internet, particularmente no ciberespaço Orkut, que, na época, apresentava relevo no âmbito de estudos de processos de subjetivações contemporâneas. Assim, a partir da noção de ética e moral proposta por Gilles Deleuze, intentase cartografar comunidades de Orkut que socializam experiências elou opiniões envolvendo o uso de psicoativos, a fim de estudar o modo como esses sujeitos vivem essas experiências. O foco de investigação é colocar em análise o modo como essas experiências, envolvendo estados alterados de consciência, foram narradas, bem como as articulações entre moral e ética estão delineadas. Para tanto, faz-se uso do método cartográfico, objetivando estudar a dimensão processual da subjetividade e de seu processo de produção.

Palavras-chaves: experiência com psicoativos, produção de subjetividade, ética, comunidades Orkut.

\section{BETWEEN THE INTENSITY OF LIFE AND THE "SCUFF" OF DEATH: AN EXPERIENCE OF PSYCHOACTIVE MAPPING}

\begin{abstract}
This work is the result of a scientific initiation research, funded by $C N P Q$ in 2008, which investigated the production processes of subjectivity on the Internet, particularly in Orkut cyberspace, which at the time, had carried out studies in the processes of contemporary subjectivity. Thus, from the notion of ethics and morality proposed by Gilles Deleuze, it sought to map Orkut community experiences in socializing and/or opinions involving the use of psychoactive drugs and to study how these people live through their experiences. The research

\footnotetext{
^ Pós-Doutora pela Universidade do Minho em Portugal e pela Universidade Federal de Minas Gerais (UFMG). Docente dos cursos de Graduação e Pós-graduação de Psicologia da Universidade Federal de Santa Catarina (UFSC) e coordenadora do Núcleo de Pesquisa Modos de vida, Família e Relações de Gênero (Margens/UFSC).

E-mail: juracy@cfh.ufsc.br

E-mail: nanduluiz@gmail.com
}

$\star \star$ Psicólogo. Mestrando em Psicologia Social na Universidade Federal de Santa Catarina.
\end{abstract}


focus is based on analysing how these experiences which involved altered states of consciousness were reported, and how the connection between morality and ethics are delineated. For this, one uses the mapping method to evaluate the procedural dimension of subjectivity and its production process.

Keywords: experience whith psychoactives; production of subjectivity; Ethics; Orkut communities.

\section{SubJeTIVIdAde E História...}

Pensar em subjetividade, tal como a proposta deste texto sugere, é pensá-la como uma produção inscrita no social e no processo histórico. Sendo assim, "efeito de uma processualidade complexa na qual diversos elementos - humanos e inumanos - se entrelaçam, sendo dotada de plasticidade e não determinada por alguma essência central e transcendente, a subjetividade é, aqui, colocada na perspectiva do tempo, sendo este considerado como multiplicidade virtual, como um todo aberto e extemporâneo" (FONSECA, 2009, online). Ainda neste mesmo texto, a autora desenvolve um pouco mais esta noção:

Ao referir-se ao homem, Nietzsche nos dizia algo que pode ser acolhido no contexto de nossa argumentação: “... o ainda não domado, o eternamente futuro, que não encontra sossego de uma força própria que o impele, de modo que seu futuro, uma espora, mergulha na carne de todo o presente". Assim, se o presente é perturbador e exige uma atenção redobrada, se os instrumentos até agora utilizados para mapeá-lo parecem insuficientes, se as forças que nos rodeiam e nos impelem a velocidades vertiginosas ainda não se fazem claras aos nossos olhos, temos, aí, razões para alçar-nos com mais garra à altura ${ }^{1}$ desse desafio, pois é ainda com Deleuze que viemos a formular a necessidade de estar à altura do que nos acontece - eis a ética essencial. (FONSECA, 2009, online)

Pensar em uso de psicoativos no mundo contemporâneo, segundo os estudos de subjetividade, é entendê-lo nas suas articulações com a história. Assim, é preciso levar em conta, então, as construções sócio-históricas do que consideramos drogas, às quais conferimos, enquanto sociedade, um estatuto de ilegalidade ou legalidade. Por isso, é preciso complexificar o debate sobre a questão, investigando as diferentes relações que sociedades constróem com relação ao uso de substâncias psicoativas, percebendo que investigar diferentes períodos históricos e diferentes culturas, auxilia a pensar como foi se construindo, na sociedade ocidental e brasileira, o dependente químico, bem como a ideologia do "combate às drogas". Segundo Vargas (1998), o saber e as práticas médicas oferecem os principais argumentos de legitimação da war on drugs, ${ }^{2}$ a saber, que o consumo não medicamentoso de drogas não é compatível com os ideais de saúde e de bemestar que também a medicina nos impõe a buscar. 


\section{BREVES CONSIDERAÇÕES SOBRE O USO DE PSICOATIVOS NO CONTEMPORÂNEO}

Vargas(1998) considera que é paliativo dizer que as sociedades contemporâneas declaram, de modo geral, e com força nunca antes vista, guerra às drogas, fazendo assim com que estas, diga-se de passagem, se tornassem umas das coisas mais lucrativas e insidiosas ${ }^{3}$ deste planeta. Nesse sentido, as implicações que a política proibicionista traz em termos de políticas públicas punitivistas atualizam processos de exclusão que historicamente marcam o cenário brasileiro. Além disso, deve-se levar em conta que o sistema penal é seletivo pois orienta o julgamento de delitos de uso e tráfico. Resultando, então, nos atributos pessoais do agente, tais como raça, geração e classe social que acabam determinando a imputação de crimes.

Ainda que o uso de psicoativos esteja sempre inserido numa série de relações de saber-poder que atravessam a experiência dos usuários, e por isso produzem sua enunciação, aqui trataremos especificamente das relações éticas e morais que usuários de psicoativos constroem para relatar, na medida do dizível, suas experiências ruins/aversivas envolvendo substâncias psicoativas não medicamentosas. Ao traçar uma analogia com o conceito foucaultiano de "dispositivo de sexualidade", Vargas (2001) fala numa espécie de dispositivo ${ }^{4}$ das drogas para se referir à ambiguidade contemporânea que proíbe e incita cada vez mais o consumo de substâncias psicoativas para finalidades absolutamente diversas. Se é em nome da saúde dos corpos que o consumo não medicamentoso de drogas é combatido, é também pelo mesmo motivo, em nome dos mesmos corpos, que o consumo medicamentoso de drogas é incitado. Deste modo, pensar num dispositivo das drogas é problematizar a assimetria moral existente entre psicoativos lícitos e ilíticos. Isso porque os meios sociais estão sempre tensionando e relativizando essas partilhas morais. Exemplos não faltam: um anabolizante cai muito bem nas academias de musculação; uma anfetamina para emagrecer; um comprimido ecstasy para aguentar horas dançando nas rodas de amigos; um cigarro para dar uma pausa ao pensamento ou relaxar de situação estressante/decisiva; ou ainda, uma "cervejinha" com amigos do trabalho. Até em tempos de lei seca, ${ }^{5}$ cai muito bem.

\section{DAS EXPERIÊNCIAS COM PSICOATIVOS}

Para Leiris (apud PERLONGHER, 1994), as experiências de êxtase são reconhecidas sob três variantes de ruptura: estar fora de si, projetar-se num outro mundo, e, virar outro. No mundo contemporâneo, "através das drogas e outros estímulos, as pessoas encontram meios de atingir o transe". Define Lapassade (apud PERLONGHER, 1994, p. 10):

A consciência modificada se caracteriza por uma mudança qualitativa da consciência ordinária, da percepção do espaço e do tempo da imagem do corpo e da identidade pessoal. Essa modificação supõe uma ruptura, produzida por uma indução ao término da qual o sujeito entra num 'estado segundo'. 
Já Rodrigues (1999) fala em desterritorizar, ou seja, em desfazer/refazer conexões, abandonar/construir campos de consistência (de uma relação, de uma língua, de uma habitação, de uma referência, de um modo de vida...), deixar-se atravessar por fluxos advindos dos encontros com outros corpos (humanos e não humanos [a droga é um corpo...]), deixar-se intensificar em direção a outros territórios; é, enfim, abrir-se aos devires. Teríamos, então, muito mais do que uma vida em extensão, uma, em intensidade. Deleuze e Guatarri (1997) falam de corpos povoados por intensidades. Todos esses conceitos trabalham a droga como possibilidade de novos arranjos, novas percepções sobre si mesmo e a realidade que o cerca. Um rearranjo de um todo, é, segundo Rodrigues (1999, online):

Estar atento a tudo aquilo que permite à vida se expandir, se inventar, a ativar as forças, e ser rigoroso com tudo aquilo que surja como reativo, como despotencializante, seja de um sonho, de um movimento, de um vínculo, de uma expressão.

Rodrigues (1999) também traz a droga como potência transformadora (seja ela criadora ou destrutiva). É seu segundo momento despotencializador que merece atenção, e ele só pode ser reconhecido se tomarmos como princípio essa regra fundamental da experimentação, que é a da prudência. Não há nada que seja em-si bom ou mau, como já demonstrou extensivamente Espinosa com sua Ética não normativa. Assim, todas as entradas podem ser boas, a questão é o que fazer com elas. O que fazer e como fazer. Sendo os critérios extramorais, a única sugestão é a da prudência.

\section{Dos conceitos disparadores: ética a Partir de Gilles Deleuze}

A discussão que Deleuze desenvolve sobre ética está bastante vinculada ao pensamento espinosista, que trabalha com uma ideia de plano comum de imanência ou consistência "em que estão todos os corpos, todas as almas, todos os indivíduos" (DELEUZE, 2002, p. 126). O mesmo especifica o que seria pensar com Espinosa a questão de viver num plano de consistência:

Esse "plano de imanência" ou de consistência não é um plano no sentido de desígnio do espírito, projeto, programa, é um plano no sentido geométrico, seção, interseção, diagrama. Então, estar no meio de Espinosa é estar nesse plano modal, ou melhor, instalar-se nesse plano; o que implica um modo de vida, uma maneira de viver (DELEUZE, 2002, p. 127).

$\mathrm{Na}$ medida em que recusa uma definição meramente biológica do corpo, ou seja, uma noção de organismo composto de órgãos e funções, Deleuze (2002) fala em corpo comportando uma infinidade de partículas em relações de repouso e movimento, velocidades e lentidões. Outra propriedade fundamental de um corpo é a capacidade de afetar e ser afetado por outros corpos. Por entender que corpos e almas não são substâncias, nem sujeitos, mas sim, modos de vida, Deleuze pensa em ética, não como moral, mas como estudos dinâmicos e cinéticos, ou seja, um estudo da ordem das velocidades e lentidões e dos "poderes de afe- 
tar e de ser afetado nesse plano de imanência" (DELEUZE, 2002, p. 130). Isso porque Espinosa amplia as possibilidades de existência, pois segundo ele: "Não sabeis o que sois capazes, no bom como no mau, não sabeis antecipadamente o que pode um corpo ou alma, num encontro, num agenciamento, numa combinação" (apud DELEUZE, 2002, p.130).

Ao entender ética como tipologias de modos de existência imanentes, desarticula-se quaisquer sistemas de julgamento, pois Moral refere-se à existência com valores transcendentes, produzindo oposição de valores como O Bem e $\mathrm{O}$ Mal. Para entendermos um pouco melhor o que este filósofo quer dizer sobre os equívocos do pensamento moralizante, citaremos o próprio autor:
A oposição dos valores (Bem/Mal) é substituída pela diferença qualitativa dos modos de existência (bom/mau). A ilusão dos valores se confunde com a ilusão da consciência: porque a consciência é essencialmente ignorante, porque ignora a ordem das coisas e das leis, das relações e de suas composições, porque se contenta em esperar e recolher o efeito, desconhece toda a natureza. Ora, basta não compreender para moralizar. É claro que uma lei, desde o momento em que não a compreendemos, nos aparece sob a espécie moral de um "Deve-se". Se não compreendemos a regra de três, nós a aplicamos, nós a consideramos um dever. Se Adão compreende a regra da relação de seu corpo com o fruto, entende a palavra de Deus como uma proibição. Mas ainda, a forma confusa da lei moral comprometeu de tal modo a lei de natureza, que o filósofo não deve falar em lei da natureza, mas somente de verdades eternas: "É por analogia que a palavra lei se encontra aplicada a coisas naturais e, de maneira geral, por lei, entendemos um mandamento..." [...] A lei é sempre a instância transcendente que determina a oposição dos valores Bem/Mal, mas o conhecimento é sempre a potência imanente que determina a diferença qualitativa dos modos de existência bom/mau (DELEUZE, 2002, p. 30).

Entendedor de ética no âmbito desses corpos situados num plano de consistência, Deleuze traz a ideia de que é na imanência que os corpos vão se conduzir em consonância com suas afetações, suas velocidades e seus movimentos.

Deleuze (1992, p. 64), no breve e denso texto "Duas Questões", coloca a questão das drogas no âmbito das "velocidades, e das modificações da velocidade, aos limiares de percepção, às formas e aos movimentos, às micropercepções, à percepção tornando-se molecular, aos tempos sobre-humanos ou sub-humanos etc." (DELEUZE, 1992, p. 64). Coloca-se desafios para uma analítica da psicanálise no que tange a este tema, pois o desejo aqui entra diretamente no sistema-percepção, não sendo importante, desta forma, buscarmos como questão de pesquisa uma causalidade específica quanto ao uso de drogas, pois estas, muitas vezes, desviam de sua própria causalidade. Deleuze (1992) diz que o drogado fabrica suas linhas 
de fuga ativas. Mas essas linhas se enrolam, se põem a girar nos buracos negros, cada drogado tem seu buraco, grupo ou indivíduo, como um caracol. Assim, faz-se necessário distinguir dois tipos de experimentação envolvendo psicoativos:

O domínio das experimentações vitais e 0 dos empreendimentos mortíferos. A experimentação vital ocorre quando uma tentativa qualquer agarra você, se apodera de você, instaurando cada vez mais conexões, abrindo-se às conexões: uma tal experimentação pode comportar um tipo de "autodestruição", ela pode passar por produtos de acompanhamento ou de arrebatamento, o tabaco, o álcool, as drogas. Ela não é suicidária, na medida em que o fluxo destruidor não se rebate sobre si mesmo, mas serve para a conjugação de outros fluxos, quaisquer que sejam os fluxos. Mas o empreendimento suicidário, ao contrário, ocorre quando tudo é rebatido unicamente sobre esse fluxo: "minha" dose, "minha vez", "meu" copo. É o contrário das conexões, é a desconexão organizada, em vez de um "motivo" que serviria aos verdadeiros temas, às atividades, um único e pleno desenvolvimento como em uma intriga estereotipada, onde a droga é pela droga. [...] Tudo se rebate sobre uma linha morna suicidária [...] Narcisismo, autoritarismo dos drogados, chantagem e veneno (DELEUZE, 1992, p. 65).

Caberia uma atividade de um pesquisador ou psicólogo colocar-se como nomeador da experiência instauradora de conexões ou do empreendimento mortífero? Certamente, faríamos uso distorcido dessa teoria, afinal são linhas dinâmicas que se misturam e se interpõem a todo momento. É pertinente recuperar a ideia de cartografia que opera de modo a captar processualidades em movimento, não se colocando assim de modo a classificar, nomear, "revelar" algo até então não conhecido. Ainda que o método cartográfico seja um tópico que será mais desenvolvido mais adiante, interessa-nos aqui retomar e dimensão processual dessas linhas de experimentação que inclui a experiência de uso de psicoativos, bem como o exercício da recusa da moralização para refletir sobre a questão.

\section{ACOMPANHANDO PROCESSUALIDADES...}

A primeira ideia para entender-se o método cartográfico é: cartografar é acompanhar um processo e não representar um objeto. Assim, a discussão sobre cartografia se conecta a uma crítica paradigmática à modernidade, à representação, ao racionalismo, etc. Estamos falando aqui de uma discussão filosófica que se opõe ao racionalismo kantiano, enfatizando o conhecimento obtido por meio da experiência, dos sentidos, do empírico.

Como este método visa acompanhar processualidades e não representar um objeto, a opção é pela geografia (KASTRUP, 2008), na qual a processualidade ocorre a partir de uma configuração de vetores, forças ou linhas que atuam simultaneamente sobre um determinado campo. Desse modo, as configurações subjetivas 
não apenas resultam de um processo histórico, mas portam em si mesmas processualidade e guardam a potência do movimento. Assim, cartografar implica observar um campo de forças que responde pela produção da subjetividade, sejam esses vetores: econômicos, políticos, sociais, tecnológicos, linguísticos, ecológicos etc.

O mapa, nesta perspectiva, é uma espécie de todo aberto, em constante movimento, composto de múltiplas linhas heterogêneas, cujas conexões podem ser alteradas e rompidas. Deleuze e Guattari (1995, p. 22) afirmam: “O mapa é aberto, é conectável em todas as suas dimensões, reversível, suscetível de receber modificações constantemente". Fazer um mapa é então captar linhas, movimentos, um plano de forças. Enquanto o decalque traz consigo uma forma já constituída, uma cartografia intenta captar dois planos: plano de formas, que produz efeitos de forças mais estáveis; e o plano de força, que guarda uma maior potência de movimento. Mesmo que toda forma seja resultado de agenciamentos que se dão no plano de forças, isso não exclui que esse plano de forma esteja em constante formação; ainda que apresente certa ideia de estabilidade, as formas são agregadas de múltiplas forças. Virgínia Kastrup (2008, p. 487-488) assim condensa algumas pistas ao pesquisador que pretende traçar uma cartografia, delineando também questões epistemológicas engendradas no ato de cartografar:

Propondo-se ao acompanhamento de um processo, o movimento do território cartografado faz parte da proposta da pesquisa cartográfica. A habitação do território investigado é condição para detectar as forças moventes que acionam este movimento, pedindo passagem e expansão. Cabe ao cartógrafo cultivar uma atenção fina, em sintonia com o coletivo de forças. De tal experiência, o cartógrafo não sai imune. Faz parte da pesquisa a transposição de limites das formas objetivas, mas também das subjetivas, inclusive a do próprio pesquisador. Subjetividades coletivas e campos problemáticos são constantemente redesenhados à luz de novos desafios e exigências encarnadas nos dispositivos da pesquisa .

\section{O SITE $O_{\text {RKUT }}$}

Dentro do universo do ciberespaço, propõe-se uma reflexão sobre o site de relacionamentos Orkut, ferramenta de relacionamento social que conecta pessoas, visando ampliar seus círculos sociais. Neste site, os usuários criam um profile (perfil), por meio da qual se relacionam com outros usuários e podem participar de discussões em fóruns de comunidades.

O Orkut possui em sua estrutura, além das ferramentas necessárias para navegação, diferentes espaços como: foto principal; perfil do usuário; álbum de fotos; álbum de vídeos; depoimentos; livro de recados; rede de amigos e comunidades. Estas últimas mostram-se, em grande parte, promissoras para a pesquisa em questão, posto que, por meio de seu conjunto, tomam posição diante de variados 
temas. "Fator que inicialmente pode passar despercebido, mas que revela sua importância ao se refletir sobre as concepções identitárias e manifestações estéticas presentes" (MEUCCI; MATUCK, 2005, p. 176) no universo destes ciberespaços.

Pode-se entender que a participação em uma comunidade funciona como uma "técnica de si", no sentido foucaultiano, por levar o usuário a pensar sobre si e a escrever sobre si, proporcionando uma ampla visibilidade e tornando-o permanentemente exposto a múltiplos olhares, à vigilância constante e consequente regulação de suas condutas. As "técnicas de si" referem-se à relação que os indivíduos estabelecem consigo mesmos e são definidas como aquelas que:

[...] permitem aos indivíduos efetuar, por conta própria ou com a ajuda de outros, certo número de operações sobre seu corpo e sobre sua alma, pensamentos, conduta, ou qualquer forma de ser, obtendo assim uma transformação de si mesmos... (FOUCAULT, 1988, p. 48).

Entendemos que o ingresso nestas comunidades virtuais produz efeitos nos sujeitos que participam delas, ao se depararem com diferenças no modo como as pessoas se conduzem perante, por exemplo, estados alterados de consciência, "afetando e reconfigurando subjetividades e respondendo, também, de modo recíproco e indissociável, pela invenção de mundos para além dos limites daqueles já constituídos, expandindo-os e diversificando-os." (KASTRUP, 2008, p. 476).

Para participar de uma comunidade do Orkut, o usuário realiza exercícios de categorizações/narrações de si e de suas práticas e autorreflexões. Por meio desse mecanismo, inúmeras informações sobre esses usuários são analisadas, criadas e também expostas ao olhares dos outros. Desse modo, as comunidades do Orkut proporcionam ao indivíduo uma série de exercícios éticos, ou seja, de modos de condução diante do que a comunidade pretende discutir. É interessante ressaltar que o usuário que queira postar uma discussão na comunidade pode fazê-lo de forma anônima.

Existem vários outros sites que permitem, ao usuário, construir uma rede de relacionamentos e comunidades que discutam assuntos e/ou temas que seja interesse dos internautas: Facebook, Flickr, Multiply, Myspace, Twitter. O site de rede de relacionamentos mais difundido no Brasil certamente é o site Orkut, aliás tem como maioria de usuários, brasileiros. ${ }^{6}$ Sua escolha, portanto, como campo de pesquisa reside no fato de o considerarmos como um dispositivo tecnológico recente produtor de subjetividades.

O Orkut vem se configurando como um espaço de discussão de muitos assuntos cotidianos. Tanto podem ser espaços de discussão em que sujeitos se atualizam de acordo com a norma jurídico-psiquiátrica (criminalizante e patologizante), quanto há possibilidades éticas de invenção de novas formas de se conduzir perante a experiência com psicoativos. 
A análise de comunidades do Orkut e da maneira como os usuários ali se atualizam, permite-nos pensar a Internet não simplesmente como uma tecnologia de informação e comunicação, mas também como uma das ferramentas de compreensão da construção e produção de subjetividades no cenário contemporâneo. Seus signos permitem refletir sobre como as experiências com o corpo estão sendo provisoriamente narradas, assinalando para o entendimento de que as discussões vinculadas a essas comunidades trazem em seus conteúdos modos de ser, estar, sentir e agir no mundo, para além, talvez, dos discursos instituídos no tecido social.

Considerando que as comunidades são dispositivos interessantes de discussão de diversos assuntos e de produção de percepção de experiências, aqui foram selecionadas aquelas que mais se mostraram promissoras para o nosso objetivo: investigar as experiências éticas de usuários de substâncias psicoativas. Assim, investigou-se as seguintes comunidades:

Comunidade Discussão sobre Ecstasy v4 - discute o uso, a experiência e os efeitos da metilenodioximetanfetamina (MDMA), mais conhecida como ecstasy;

Comunidade Bad trip - abre espaço para discutir as experiências negativas envolvendo uso de psicoativos.

Comunidade Experiência Psicodélica - compartilha formas de experiência de estados alterados de consciência, envolvendo uso de psicoativos ou não;

\section{CaracterizaÇão do CAMPo}

O processo de escolha das comunidades se deu a partir do delineamento dos objetivos propostos pela pesquisa, ou seja, as que falavam sobre experiências envolvendo uso de psicoativos eram escolhidas para análise. Constatada a existência de uma comunidade afinada com objetivo do projeto, solicitava-se a entrada nela, porém não participava das discussões da comunidade, que se encontram em domínio público a partir desse momento. Durante o tempo de cinco meses, a comunidade era acompanhada pelo pesquisador, que inspirado na cartografia, procurava delinear tanto discussões mais estabilizadas, repetidas, quanto narrativas que fugiam do cotidianamente encontrado naquele ciberespaço.

Assim, com o tempo, ao observar a comunidade na condição de membro, habitando o território "comunidade do Orkut", foi possível, a partir daí, acompanhar algumas processualidades nas narrativas de experiência envolvendo psicoativos. Dessa maneira, pudemos analisar alguns trechos para colocar em análise de modo estão articulados aspectos éticos nessas narrativas.

Antes de entrar nas narrativas propriamente ditas, é importante acompanharmos como são essas comunidades, nas quais são discutidas temáticas tão diversas e até polêmicas. Vimos que todo usuário deste site tem um perfil, no qual se tem a possibilidade de não somente construir uma rede de amigos que tam- 
bém são usuários, mas também participar de comunidades de seu interesse. Essas comunidades possuem: um título; uma descrição breve com informações sobre o que se pretende discutir, a quem se destina, ou qual ideia pretende divulgar e/ ou circular na rede; uma foto; vários tópicos que os participantes podem sugerir para que sejam discutidos pelos outros membros deste ciberespaço; e uma lista de outras comunidades relacionadas àquilo que se pretende versar. No que se refere ao tempo de existência das comunidades, não foi possível ter acesso a esse dado, visto que não há esse dado disponível para consulta. As que preliminarmente foram observadas, estão as descritas na tabela abaixo:

\section{TABELA SOBRE AS COMUNIDADES CARTOGRAFADAS ${ }^{7}$}

\begin{tabular}{|c|c|c|}
\hline $\begin{array}{c}\text { TÍTULO DA } \\
\text { COMUNIDADE }\end{array}$ & DESCRIÇÃO & $\begin{array}{l}\text { COMUNIDADES } \\
\text { RELACIONADAS }\end{array}$ \\
\hline $\begin{array}{c}\text { Comunidade } \\
\text { Discussão sobre } \\
\text { Exctasy v4 } \\
\text { (13 membros - } \\
\text { número atualizado) }\end{array}$ & $\begin{array}{l}\text { Comunidade destinada a discus são sobre o uso do } \\
\text { MDMA, mais conhecido por ecstasy, que é uma } \\
\text { droga sintética, neurotóxica, cujo efeito na } \\
\text { fisiologia humana é o bloqueio da reabsorção da } \\
\text { serotonina, dopamina e noradrenalina no cérebro, } \\
\text { causando euforia, sensação de bem-estar, } \\
\text { alterações da percepção sens orial do consumidor } \\
\text { e grande perda de líquidos. Aqui é o lugar certo } \\
\text { para sanar dúvidas e curiosidades sobre a preciosa } \\
\text { pílula. Sugestões serão sempre bem vindas, se } \\
\text { tiver alguma crítica ou sugestão para melhorar a } \\
\text { comunidade, sinta-se a vontade. } \\
\text { O dono e os moderadores não terão } \\
\text { responsabilidade pelo o que vier a ser postado } \\
\text { pelos usuários. } \\
\text { *Regras }\end{array}$ & $\begin{array}{l}\text { Sem comunidades } \\
\text { relacionadas }\end{array}$ \\
\hline $\begin{array}{c}\text { Comunidade Bad } \\
\text { trip } \\
\text { (1665 membros) }\end{array}$ & $\begin{array}{c}\text { Uma Bad Trip é uma experiência profundamente } \\
\text { desagradável usando uma droga alucinógena } \\
\text { como um LSD ou psilocybin.....ou qualquer outra } \\
\text { droga que bate errado, causado um ou mais efeito } \\
\text { indesejados comuns da droga: } \\
\text { - Reação de Pânico } \\
\text { - Ampliação dos medos incons cientes } \\
\text { - Auto-Agressão } \\
\text { - Tendência Suicida } \\
\text { - Medo de enl ouquecer ou da incapacidade de } \\
\text { retornar ao normal } \\
\text { - Percepção de rápido envelhecimento de si } \\
\text { próprio ou de outros } \\
\text { - Depressão Profunda }\end{array}$ & $\begin{array}{c}\text { Viagem astral; } \\
\text { Projeção astral; } \\
\text { Amanita Muscarita; } \\
\text { Os Poderes da Mente; } \\
\text { Caçadores da Rave } \\
\text { Perdida. }\end{array}$ \\
\hline
\end{tabular}




\begin{tabular}{|c|c|c|}
\hline $\begin{array}{c}\text { TÍTULO DA } \\
\text { COMUNIDADE } \\
\end{array}$ & DESCRIÇÃO & $\begin{array}{l}\text { COMUNIDADES } \\
\text { RELACIONADAS } \\
\end{array}$ \\
\hline $\begin{array}{c}\text { Comunidade } \\
\text { Experiência } \\
\text { Psicodélica } \\
\text { (757 membros) }\end{array}$ & $\begin{array}{c}\text { Comunidade criada com a finalidade de guiar as } \\
\text { pessoas em seu estado alterado de consciência, } \\
\text { tendo como guia o Universo. } \\
\text { Toda e qual quer informação é mais do que bem } \\
\text { vinda, o objetivo também é compartilhar } \\
\text { experiências, agradeço desde já. } \\
\text { Tais experiências de consciência expandida } \\
\text { podem ocorrer de diversas formas: privação } \\
\text { sensorial, exercícios de yoga, meditação } \\
\text { disciplinada, êxtases religiosos ou estéticos. Mai s } \\
\text { recentemente elas se tornaram disponíveis a } \\
\text { qualquer um mediante a ingestão de drogas } \\
\text { psicodélicas como LSD, pscilocibina, mescalina, } \\
\text { DMT, etc. } \\
\text { Óbviamente, a droga não produz a experiência } \\
\text { transcedental. Ela apenas age como uma chave } \\
\text { química - ela abre a mente, liberta o sistema } \\
\text { nervoso de seus padrões e estruturas ordinárias... } \\
\text { "...com os sentidos, o pensamento e o intelecto } \\
\text { subjugados por compl eto, consagrado unicamente } \\
\text { à liberação final, e isento de anseios, aversões } \\
\text { e temores, o sábio é livre para sempre." } \\
\text { extraí do do Mahâbhârata,uma epopéia indiana do } \\
\text { século } 5 \text { a.C. }\end{array}$ & $\begin{array}{l}\text { Tommy chong é o } \\
\text { cara!; Breakfast of } \\
\text { champions; Não te } \\
\text { interessa; porco!; } \\
\text { Falou mal; quebro tua } \\
\text { cara; Contemplação; } \\
\text { O que acontece } \\
\text { depois da morte?!; } \\
\text { Tenho asma e fumo } \\
\text { igual; Obrigado } \\
\text { Albert Hofmann; Se é } \\
\text { de boa Deus perdoa. }\end{array}$ \\
\hline
\end{tabular}

\section{CORPO SEM ÓRGÃOS \& EXPERIÊNCIAS COM ECSTASY: DISCUSSÕES SILENCIADAS}

Nesta comunidade, o dado mais intrigante, que emerge num primeiro momento, é a quantidade de dissoluções que já experenciou: quatro. Acusados de fazerem apologia às drogas ou "promoção de atividades perigosas", estes usuários tornam a criar este ciberespaço novamente e insistem em resistir por meio de suas discussões. Na primeira vez em que entramos nesta comunidade, esta encontravase na terceira versão, porém, já na confecção deste texto, a mesma foi dissolvida novamente... Ao digitar no campo de busca de comunidades as palavras "discussões sobre ecstasy", lá estava novamente com quase quinhentos participantes e com um símbolo indicando o número de vezes que foi dissolvida. Como as discussões do fórum são zeradas quando banidas, os usuários (re)fazem seus debates. Onde antes a discussão era mais densa e havia um grande compartilhamento de experiências, agora as pessoas se limitam a perguntar quem tomou tal tipo de ecstasy, se é boa ou não, divulgar sites que catalogam todos os tipos de ecstasy ou que vendem o psicoativo por internet até o próximo click "denunciar abuso".

Pela descrição da tabela anterior, percebemos que os moderadores da comunidade explicitam que não se responsabilizam pelos conteúdos postados pelos usuários. Pelo risco da comunidade ser banida novamente, eles evidenciam esse descompromisso com os conteúdos circulados nesse espaço, registram a palavra 
"Regras", como se fosse para enumerar algumas condutas não permitidas naquele "lugar", porém o mesmo não expõe nenhuma prescrição de conduta para regular a participação dos participantes da comunidade "Discussões sobre Ecstasy v4", limitando-se a colocar a palavra "regras".

Antes de adentrar nas bad trips, é interessante focarmos um pouco as experiências potencializadoras com psicoativos, ou aquele tipo de experimentação vital que Deleuze (1992) chama de instauradora de conexões. Ao visitar um poema descrito por um experimentador nas primeiras visitas a campo, observamos alguns pontos de encontro com outro conceito da filosofia da diferença...

Chegada à noite/ Tornamo-nos então, superiores, ficamos excelsos/ Ultrapassamos os limites da experiência possível/ No que é Metafísico!/ Nas batidas da música/ Pernas, braços, mãos, corpo, pensamentos/ Tudo parece estar fazendo parte de uma música psicodélica!/ Transcendemos/ Sem que percebamos/ Evoluímos, e crescemos/ Com essa eletroacústica/ Correndo por todo o nosso corpo/ Subimos para um plano superior/ Alçamos então, voo/ Desordenamos, desorganizamos Perturbamos, atrapalhamos! Com pés descalços, batendo, sustentamos polêmicas/ $\mathrm{Na}$ areia branca/ Atordoamos, fazemos perder o controle/ Transtornamos/ De repente, passamos a/ Privar-nos da razão, do entendimento/ Desvairamos/ Iludimos, entramos em um completo/ Delírio/ Neste momento os olhos enchem de cores e flores/ Alucinamos/ Tivemos um arrebatamento íntimo/ Completas admirações, estamos em um estado espiritual de união com o divino, coisas sobrenaturais/ Ficamos pasmados, assombrados/ Encantamos, inebriamos/ [...]. (Texto extraído da página do Orkut de um experimentador).

O conceito da filosofia da diferença que podemos remeter ao poema acima é o de corpos sem órgãos. Para Deleuze e Guattari (1997), um corpo sem órgãos é feito de tal maneira que ele só pode ser ocupado, se povoado por intensidades. Somente as intensidades passam e circulam. [...] O $\mathrm{CsO}^{8}$ é o campo de imanência do desejo, o plano de consistência própria do desejo. [...] O CsO é desejo, é ele e por ele que se deseja (DELEUZE; GUATTARI, 1997, p. 28). Ato contínuo, o corpo aqui entra em outro estado, indo além da "experiência possível”, Segundo Oliveira (2007, p. 85), "o organismo orientado pela sobrevivência e pela reprodução, contrapõe-se ao corpo sem órgãos, composto por todo um potencial humano voltado para o prazer e o desejo". Destituído de organização, está aberto a múltiplas conexões... Assim o poema percorre temas como a desterritorialização, de dissolução de eu, delírio etc. 


\section{Que SAIR O QUÊ? SAIR PARA QUE PESSOAL?? APESAR DE SER BAD, AINDA É UMA TRIP!}

Com Deleuze (1992), recusamos a busca de uma causalidade específica do uso de substância psicoativas, pois as linhas de vida, que, algumas vezes, "roçam" na morte, fazem parte das forças que estão em jogo nos agenciamentos que engendram a experiência com psicoativos. Mencionamos nesse texto, ainda, as linhas instauradoras de conexões e dos empreendimentos mortíferos. É na pista destes que seguiremos.

Na caracterização da comunidade, temos uma breve descrição das sensações de uma bad trip, numa linguagem próxima à biomédica: reação de pânico; ampliação dos medos inconscientes; autoagressão; tendência suicida; medo de enlouquecer ou da incapacidade de retornar ao normal; percepção de rápido envelhecimento de si próprio ou de outros; depressão profunda. Vale pontuar que é o moderador da comunidade que descreve com esses termos. Ou melhor, o que podemos observar é o atravessamento do discurso médico nesta descrição. E, por conseguinte, uma vulgarização e banalização da linguagem biomédica no âmbito do senso comum. Evidentemente, não nos contentaremos com tal descrição psicopatológica das funções psíquicas, pois, além de ser uma linguagem generalista e superficial, não contempla a complexidade de signos presentes nesse universo de experiência. Um primeiro erro é ater-se ao olhar psicopatológico sobre esta experiência. Além das funções psíquicas alteradas, há também singularidades nas vivências dessas alterações, bem como a forma como esses sujeitos vão narrar tais experimentações. Os estudos de semiologia das alterações das funções psíquicas confirmam esta discussão, ao propor, não uma psicopatologia da terceira pessoa - sem lugar para o vivido, com descrições objetivas dos comportamentos, mas uma psicopatologia da primeira pessoa - ,enfatizando como a pessoa vive essa experiência, e se singulariza perante ela.

$\mathrm{Na}$ leitura das falas dos sujeitos, encontramos não somente narrativas de experiências, mas também sugestões para "sair" de uma bad trip, opiniões individuais, dentre outros tipos de comentários. Muitos destes foram postados de forma anônima, de modo que, mais uma vez, o proibicionismo tanto do uso, quanto até de um mero partilhar da experiência, se atualiza neste espaço.

As configurações dessas experiências são absolutamente diversas, como se pode depreender da leitura dos trechos a seguir:

"Minha primeira bad trip foi ontem de 1sd...péssimo! cismei q eu odiava uma menina q mora comigo, queria q ela ficasse longe de mim, nao quis deixar ela entar no taxi na hora de ir embora... q bosta! ela ficou mó chateada, chorou e eu so ria da cara dela... o pior é q eu gosto dela de verdade... mas a onda foi errada saca... ela vai ficar um bom tempo chateada..."

“... já tive bad de achar q tava com câncer, de achar q ia morrer subitamente, de ataque cardíaco... sem contar a sensação de 
perseguição, de ouvir coisas esquisitas... de assistir tv e não entender nada o q tá se passando... mas bad trip foda mesmo foi essa do câncer, pira total!"

"a minha também foi com bala (coração branco) fiquei pirando com as batidas do meu coração pensava q ia ter um ataque, meu estômago parecia q tava andando e sem conta q qdo bateu a loucura tbem fiquei em pânico parecia q todo mundo tava olhando pra mim com dó sei la ai eu queria me afasta do povo nao tinha vontade de fala, mais precisava ta perto da minha amiga alguem tinha q fica abraçado comigo meu corpo treminha inteirinho o pior e q chegava uns mané e ainda falava nossa a mina ta muito mauuu, ai eu ficava pior ainda, nao sentia minhas pernas parecia $\mathrm{q}$ tava flutuando nao tinha noçao de espaço, sentia uns calafrio nervoso subia das pernas e esquentava na nuca, me sentia muito quente mais sentia frio ao mesmo tempo ai qdo eu pensava q a loucurava tava passando coisa de minutos o barato voltava mais forte ainda, nossa sei q foi fodastico queria sai da pira de qualquer jeito fiquei horas assim, so faltei ver guinomos hauhaua nao desejo isso pra ninguem so quem teve sabe como e, na minha cabeça eu ja tava preparada pra morre balas nunca mais o pior e q eu tbem to me recuperando ainda, faz uns 5 meses isso e tipo fiquei muito sensível c eu bebo muito eu ja começo a pira ai parece q volta algumas coisas aff e horrivel nunca mais!!!!"

"na real.. quem diz que curte bad trip nunca teve uma... fala sério..."

São vivências muito fortes e que marcam, de modo especial, a existência dessas pessoas. Algumas mudam seu modo se vida, outras continuam sem grandes alterações, outras ainda relatam ter revelações divinas, ou seja, condutas absolutamente diversas, e sem julgamento moral de seus atos. Há muito mais o discurso do que eu vivi foi ruim, do que o que eu fiz foi errado. Durante a leitura dos debates, uma das questões que nos interessava nessa comunidade é a continuidade do uso de drogas após essas experiências ruins. Alguns pararam, outros se tornaram religiosos, outros ainda mantiveram o hábito. Sobre estes últimos é que vamos nos deter um pouco. A recalcitrância dessas práticas é algo a ser repensado. Nesse sentido, Vargas (2006) aponta o descompasso entre o conhecimento autorizado adquirido e a persistência dos usuários na prática dessas atividades. Os pesquisadores que produzem os saberes "oficializados" estão sabendo ouvir estas experiências? Temos aí uma questão interessante de ser analisada, pois ao pensarmos nos planos de formas e forças, tal como foi desenvolvido na parte metodológica, observaremos que se ater no plano da forma de uma experiência "profundamente desagradável" com psicoativos é desprezar todo campo de forças e agenciamentos engendrados no fenômeno. 
"Será que devo parar... Ou isso foi apenas uma bad trip qualquer... Porque sinceramente não quero parar não, já to com saudade da marijuana."

"Putz uma vez fiquei com uma voz tenebrosa na cabeça dizendo morreu... morreu... muito bizarro, a maioria das minhas trips são ruins... mas mesmo assim naum paro..."

No intuito de obtermos elementos para refletirmos sobre a continuidade do hábito, pensamos com Vargas (2006) o conceito de jogos profundos. Ao levar em conta que essas pessoas seguem movimentos que as levam a fazer algo que as surpreende, sendo, de certa forma, conduzidas ligeiramente pela ação, temos que, nem psicoativos, tampouco usuários, detêm o controle sobre a situação. Desse modo, percebe-se a ocorrência de:

[...] eventos que escapam a uns e a outros, de eventos que, consequentemente, implicam doses mais ou menos elevadas de abandono ao curso da experiência ou ao desenrolar dos acontecimentos. O que torna, portanto, paradoxais as práticas de consumo não medicamentoso de drogas é que essas alterações intensivas, que implicam abandono ou dissolução do eu, são auto-engendradas, são voluntariamente visadas, são meticulosamente preparadas. Esse ponto é decisivo: deslocamento, movimento para fora, arrebatemento, transformação, "sair de si” (VARGAS, 2006, p. 593).

O conceito de jogos profundos, criado por Jeremy Bentham e citado por Clifford Geertz, avança na discussão desses jogos que escapam do controle dizendo que "são apostas tão altas que, da perspectiva utilitarista, é irracional que os homens se engajem nele(s)" (GEERTZ apud VARGAS, 2006, p. 600). Nesses, engajam-se num tal modo, frequentemente e apaixonadamente, e mesmo diante de uma punição legal (GEERTZ apud VARGAS, 2006, p. 601), ou risco de roçar a morte, persistem em lançar-se à experiência.

Ao entender que as linhas de experimentações vitais e dos empreendimentos mortíferos se misturam, enrolam-se e se põem a girar nestas dinâmicas experiências com psicoativos, a próxima narrativa revela uma ambivalência moral, que se atualiza na indecisão de parar ou não com o uso. Segundo este usuário:

\footnotetext{
"bad de cocaina eh mto chato

dah moh depressao, parece q o coraçao vai pular fora...

to tentando parar de usar

além de acabar com meu dinheiro todo, ta me fazendo mto mal

e essas bad's tão enchendo o saco

o foda eh q eh mto bom usar essa merda"
} 
A cocaína, na fala anterior, é simultaneamente fonte de prazer e desprazer para este usuário, que permanece na dúvida de interromper o vício: submeter-se ao prazer que ainda se mantém, a despeito dos prejuízos pessoais provocados pelo uso? Deste modo, coloca-se a questão de reiterar a mistura móvel de vida e morte inscritas nas narrativas dessas experiências.

E por último, a última fala traz um ponto muito importante que estende, mas não escapa do assunto desenvolvido nesta comunidade. Uma ideia, inclusive, que introduz a próxima comunidade a ser analisada: a de que não é apenas com drogas que temos nossas bad trips de cada dia. Elas fazem parte da vida e é do campo da negociação cotidiana que requer mobilização do corpo e alma, de energia, de sangue, de ossos, de músculos, de memória, de desejos, de ódios para tornar nossa vida viável.

$$
\begin{aligned}
& \text { isso que eh bad trip! } \\
& \text { bom } \\
& \text { qua - cabou o namoro } \\
& \text { qui - fui mandado embora } \\
& \text { sex - expulso de casa }
\end{aligned}
$$

mas no meio de tantas "bad trip" quinta fumei um beck 2 da tarde 4 da tarde durmi e só fui acordar 8:30 da manhã de sexta com a ultima noticia (:

isso não é lindo?

hahahahahaha!

\section{EXPERIÊNCIA PSICODÉLICA: COM OU SEM PSICOATIVOS, E COM OU SEM RELIGIÃO...}

Nem as bad trips, nem estados extáticos são exclusividade dos usuários de psicoativos. Ao afirmar a possibilidade de desterritorialização e êxtase (PERLHONGER, 1994) para além do uso de sustâncias, esta última comunidade amplia os modos pelos quais antigimos estados alterados de consciência. Com um discurso bastante místico, esta comunidade compartilha, basicamente, múltiplas maneiras que os participantes utilizam para se desterritolizarem: aproveitar um final de tarde ensolarado, praticar algum esporte, meditar, usar ácido lisérgico (LSD), atingi-lo através de êxtases religiosos...

Ao abordar essas possibilidades, não se quer hierarquizar as pessoas que conseguem atingir transe sem "drogas", com relação àquelas que o alcançam com a mediação de substâncias. Pretende-se desconstruir duas ideias bastante instituí- 
das no cenário contemporâneo: as experiências de êxtase só podem ser vividas se mediadas por psicoativos e a resistência de se pensar o uso de psicoativos como a tentativa de produção de êxtase. Segundo Vargas (2001, p. 556):

Essa resistência a se pensar o consumo moderno e ocidental de "drogas" de uso "ilícito" em termos de produção de êxtase está relacionada, ao que tudo indica, com determinada apropriação da marcante diferença que há entre os códigos que regem o consumo "primitivo" e não ocidental de substâncias que, hoje, chamamos de "drogas psicotrópicas" e aqueles (ou sua perda, descodificação) do consumo moderno e ocidental. Essa diferença refere-se ao fato de que, nas condições "primitivas" e não ocidentais, o consumo de substâncias que hoje chamamos "drogas psicotrópicas" e a produção do êxtase costumam ser experiências centrais que, inseridas em grandes aparatos rituais e consideráveis produções míticas, freqüentemente remetem a um refinado código religioso. Já nas condições modernas e ocidentais de consumo, o que parece ter-se passado foi uma abrupta e radical dessacralização ou desritualização dessas práticas extáticas, impulsionada pela "desterritorialização" generalizada que o capital induz. Como assinalara Perlongher (1988: 6 e 10), estando as "drogas" de uso "ilícito" confinadas aos ermos becos da marginalidade, seus caminhos passam a seguir cada vez mais de perto os grandes fluxos internacionais de dinheiro.

Para Vargas (2001), o deslocamento da ritualização de substâncias para a desterritorialização produzida pelo capital seria, então, uma das condições de possibilidade para o modo como se foi se apagando a relação entre uso de psicoativos e a produção de êxtase. Assim, esta ideia acaba confirmando a tônica da perspectiva de Gilles Deleuze e Félix Guattari, do quanto subjetivação capitalística produz modos de vida, e, neste caso, constrói formas específicas de captura de experiência envolvendo psicoativos.

Perlongher (1994) salienta uma diferença entre o uso ritualizado de plantas de efeito psicoativo nas sociedades ditas "primitivas" e o uso "marginal" contemporâneo: enquanto o primeiro reafirma os valores culturais, o segundo opera como uma linha de fuga ou de ruptura que os desafia. Porém, a complexa modernidade não dá um sentido único para essas experiências de estados alterados de consciência. Ao pousar nesta discussão sobre religiosidade, tanto nas sociedades antigas, quanto na contemporaneidade, vemos uma relativização muito grande no que tange ao status das pessoas que usam. Transgressores? Viciados? Infantes? Religiosos? Pagãos? Seres faltantes? Selvagens? Tolos? Seres irracionais? Loucos? Dependendo do espaço e tempo que um sujeito ocupa, há diferentes posições... 


\section{CONSIDERAÇões FINAIS}

Em síntese, é preciso expandir esta questão à dualidade lei/ilegalidade e, conseqüentemente, à polêmica em torno de sua (des)criminalização (VARGAS, 1998). Voltar-se contra a naturalização da distinção entre drogas lícitas e as ilícitas, torna-se fundamental, pois é preciso não esquecer que drogas são ainda todos os fármacos. Ato contínuo, assistimos a uma repressão muito específica ao uso de drogas consideradas ilegais e uma paradoxal incitação ao consumo de drogas legalizadas, quer sob a forma de remédios prescritos pela ordem médica com vistas à produção de corpos saudáveis, quer sob a forma de drogas autoprescritas em virtude dos ideais de beleza (os anoréticos produzindo corpos esbeltos), de habilidade (os esteroides e anabolizantes produzindo corpos de superatletas) ou de "estado de espírito" (ansiolíticos e os antidepressivos produzindo corpo serenos e mansos), e mais ainda, quer do indefectível hábito, tão comum entre nós, de ingerir bebidas alcoólicas, tabaco e café (VARGAS, 2000).

Vimos também que Deleuze (1992) entende as drogas no âmbito das mudanças de velocidade, aos limiares de percepção, às formas e aos movimentos, aos tempos sobre-humanos e não humanos. Uma experiência tão antiga quanto difundida nas sociedades humanas e, pelo que se sabe, foram somente as sociedades ocidentais que declararam guerra a certos tipos de consumo dessas substâncias, condição esta produzida por diversas condições econômicas, políticas, históricas.

Habitar o território da partilha de narrativas de experiências envolvendo psicoativos nas comunidades de orkut, experimentando a leitura dessas descrições foi, nesta medida, ocasião para a problematização da subjetividade e do mundo conhecido, abrindo-o para transformações absolutamente diversas e singulares. Ainda que possamos estranhar a provisoriedade da narrativa da experiência e as limitações do próprio dispositivo utilizado - Orkut, observa-se, aqui, uma potência de problematização ética e de estranhamento desta experiência, tal como nas narrativas que vimos. Ao abandonarmos as questões que comumente as pessoas se perguntam, do por quê as pessoas se drogam ou seus significados, há que nos determos mais em "que experiência usuários e substâncias realizam?" (VARGAS, 2006). Ou ainda:

Em meio a esses corpos imateriais e a essas matérias incorpóreas, talvez possamos saber que verdade há no vinho... [...] é que o que o consumo de corpos imateriais ou matérias incorpóreas, enfim, de spirits como as "drogas", colocam em jogos são formas socialmente constituídas, entre outras mais ou menos convenientes, para agenciar, sincrônica e/ou diacronicamente "modos intensivos ou extensivos de engajamento com o mundo" (VARGAS, 2001, p. 38, grifo do autor).

As relações entre Orkut e psicoativos são tão polêmicas quanto complexas. Tanto vê-se aquele como espaço subversivo de compartilhamento de experiências envolvendo drogas, quanto pessoas atuadas em flagrantes devido ao tráfico 
de entorpecentes via Orkut. Os dispositivos legais que criminalizam o uso de drogas atravessam os modos com vêm sendo percebidas experiências com psicoativos, inclusive nesses ciberespaços, tal como vimos na comunidade se refaz a cada nova censura. Observa-se, também, que esta nova tecnologia está sendo utilizada, para o debate de movimentos sociais como o Princípio Ativo, que visa divulgar argumentos que embasem a tese antiproibicionista.

As intensividades envolvidas nestas experiências perturbam a lógica socio-político-econômica vigente, reclamando a si o direito de ter experiências singulares, marcantes e quase imprevisíveis. Estas tanto podem ser instauradora de fluxos potencializa(dores) da vida, quanto buracos negros que roçam a morte do modo muito próximo. Linhas estas que nos acompanham mesmo sem indução de psicoativos, na negociação cotidiana de forças para tornar a vida mais viável.

\section{Notas}

${ }^{1}$ apud Pelbart, Peter Pál. Prefácio. In: Fonseca, Tania Mara Galli e outra. Formas de ser a habitar a contemporaneidade. Porto Alegre: Editora da UFRGS, 2000. p. 11

${ }^{2}$ War on drugs: guerra às drogas.

${ }^{3}$ Insidioso: traiçoeiro, pérfido.

${ }^{4}$ Segundo Michel Foucault, a idéia de dispositivo seria de "um conjunto decididamente heterogêneo que engloba discursos, instituições, organizações, arquitetônicas, decisões regulamentares, leis, medidas administrativas, enunciados científicos, proposições filantrópicas. Em suma, o dito e o não dito são os elementos do dispositivo. O dispositivo é a rede que se pode estabelecer entre esses elementos" (FOUCAULT, 1996, p. 244)

${ }^{5}$ O presidente Luiz Inácio Lula da Silva sancionou, em 2008, o projeto de lei, popularizada como "lei seca", que prevê mais rigor contra o motorista que ingerir bebidas alcoólicas. O texto, aprovado pela Câmara dos Deputados no início de junho, passa a considerar crime conduzir veículos com qualquer teor de álcool no organismo. A infração será considerada gravíssima e prevê suspensão da carteira de habilitação por um ano, além de multa. Segundo a Agência Brasil (agência estatal de notícias), a lei entra em vigor assim que for publicada no Diário Oficial da União. Fonte: Jornal Gazeta do Povo Disponivel em: http://portal.rpc.com.br/gazetadopovo/vidaecidadania/conteudo. phtml?tl=1\&id=778327\&tit=Lula-sanciona-lei-seca-nas-estradas dia 12/12/2008 às $12 \mathrm{~h}$.

${ }^{6}$ Segundo dados demográficos dos usuários do site Orkut, Brasil tem o maior número de usuários com 51,17\%, seguido por Índia com 19,88\%, e pelos Estados Unidos da América com 17,01\%. Disponível no site. http://www.orkut.com.br/Main\#MembersAll dia 12/12/2008 às 13:00.

${ }^{7}$ Fonte: http:/www.orkut.com/ Visitado às 12:00h do dia 12/08/2008.

${ }^{8}$ Cso: corpo sem órgãos

\section{REFERÊNCIAS}

BRASIL. Presidência da República. Lei $N^{o} 11.705$, de 19 de junho de 2008 (Lei Seca). Disponível em: <http://www.planalto.gov.br/ccivil_03/_Ato20072010/2008/Lei/L11705.htm>. Acesso em: 12 abr. 2010.

DELEUZE, G. Duas Questões. In: LANCETTI, A. (Org.) SaúdeLoucura. São Paulo: Hucitec. 1992. n. 3, p. 63-66.

DELEUZE, G. Espinosa: filosofia prática. São Paulo: Escuta, 2002.

DELEUZE, G.; GUATTARI, F. Mil Platôs: capitalismo e esquizofrenia. Rio de Janeiro: Editora 34. 1995. v. 1. 
DELEUZE, G.; GUATTARI, F. Mil Platôs: capitalismo e esquizofrenia. Rio de Janeiro: Editora 34. 1997. v. 3.

FONSECA O acontecimentalizar nos modos de trabalhar, modos de subjetivar: por uma ontologia histórica In: ENCONTRO ESTADUAL DOS SERVIÇOS DE PSICOLOGIA NAS INSTITUIÇÕES DE ENSINO SUPERIOR DE SANTA CATARINA: POSSIBILIDADES, LIMITES E DESAFIOS, 1., 2009, Florianópolis. Anais... Florianópolis: CRP, 2009. Palestra. Disponível em: $<$ http:// www.crpsc.org.br/publicacoes/dados/arquivos/palestras/palestra_TaniaGalli. pdf $>$. Acesso em: 12 abr. 2010.

FOUCAULT, M. Microfisica do poder. Rio de Janeiro: Graal, 1996.

FOUCAULT, M. Vigiar e punir. Petrópolis: Vozes, 1988.

KASTRUP, V. O método da cartografia e os quatro níveis da pesquisa-intervenção. In: CASTRO, L. R.; BESSET, V. L. (Org.). Pesquisa-intervenção na infância e juventude. Rio de Janeiro: Nau, 2008. p. 487-488.

LULA sanciona lei seca nas estradas. Gazeta do Povo, Curitiba, 20 jun. 2008. Vida e Cidadania. Disponível em: <http://www.gazetadopovo.com.br/vidaecidadania/ conteudo.phtml?tl=1\&id=778327\&tit=Lula-sanciona-lei-seca-nas-estradas $>$. Acesso em: 12 dez. 2008.

MEUCCI, A. MATUCK, A. A criação de identidades virtuais através das linguagens digitais. Comunicação, mídia e consumo: estética da cultura midiática, São Paulo, v. 2, n. 4, p. 157-182, 2005.

OLIVEIRA, L. M. B. Corpos Indisciplinados: ação cultural em tempos de biopolítica. São Paulo: Via Lettera. 2007.

PERLONGHER, N. Droga e êxtase. Religião e Sociedade, Rio de Janeiro, v. 16, n. 3, p. 8-23, 1994.

RODRIGUES, V. Corpos em Trans(Ito): sobre drogas e outras a(fe)tivações. 1999. Disponível em: <http://www.oestrangeiro.net/index.php?option=com_co ntent\&task=view $\& i d=82 \&$ Itemid $=54$ às $22: 00$ dia 8/05/2008>. Acesso em: 15 mar. 2010.

VARGAS, E. V. Entre a extensão e a intensidade: corporalidade, subjetivação e uso de "drogas". 2001. Tese (Doutorado em Ciências Humanas: Sociologia e Política) - Faculdade de Filosofia e Ciências Humanas Universidade Federal de Minas Gerais, Belo Horizonte, 2001. Disponível em: <http://www. bibliotecadigital.ufmg.br/dspace/bitstream/1843/VCSA-78CSU2/1/entre_a_ extensao_e_a intensidade_evv.pdf>. Acesso em: 02 fev. 2010. 
VARGAS, E. V. Os corpos intensivos: sobre o estatuto social do consumo de drogas legais e ilegais. In: DUARTE, L. F. D.; LEAL, O. F. (Org.). Doença, sofrimento, perturbação: perspectivas etnográficas. Rio de Janeiro: Fiocruz, 1998. p. 121-137

VARGAS, E. V. Que guerra é essa? A propósito da partilha moral entre drogas e fármacos. Conjuntura Política, Belo Horizonte, v. 22, p. 1-4, 2000.

VARGAS, E. V. Uso de drogas: a alter-ação como evento. Revista de Antropologia, São Paulo, v. 49, n. 2, p. 581-623, jul./dez. 2006.

Recebido em: 24 de maio de 2010 Aceito em: 24 de outubro de 2011 
